\title{
La Colección de Folklore de 1921: los múltiples autores de la lírica popular
}

\author{
The Colección de Folklore de 1921: \\ Multiple authorship in folk lyrical poetry
}

\author{
Gloria CHICOTE \\ (IdIHCS, Universidad Nacional de La Plata-Conicet) \\ gchicote@yahoo.com \\ ORCID ID: 0000-0001-8534-9073
}

\begin{abstract}
Within the frame of research conducted RESUMEN: En el marco de un conjunto de into popular forms of Latin American poetic investigaciones referidas a las expresiones discourse, I suggest here an approach to the notion populares en el discurso poético iberoamericano of authorship in the Colección de Folklore that were propongo en esta ocasión abordar el problema de la collected in Argentina in 1921. This collection autoría en la Colección de Folklore reunida en intended to document popular culture manifestations Argentina en 1921. Dicha Colección tuvo el in Spanish in order to communicate them to different propósito de documentar las manifestaciones de la educational fields and as a way to consolidate the so- cultura popular vernácula para divulgarlas en called «national spirit». This political project was diferentes ámbitos educativos y consolidar, de este ordered by the ruling elite aimed to retrieve the modo, «el espíritu nacional». El proyecto político Hispanic heritage, when millions of migrants from de la elite gobernante acudió a la recuperación del different European countries were transforming the legado hispánico colonial en un momento en que ethnic and social shape of the newly independent millones de inmigrantes procedentes de diferentes country. This work explores texts authorship, more países europeos estaban cambiando la conforspecifically in folk lyrical texts which entail a mación étnica y social del joven país independiente. contact between orality and writing. Likewise, I will En esta presentación discuto el tema de la autoría en examine the figures such as author, reader, copyist el corpus mencionado, particularmente en textos and collector, among other possible representations. líricos populares en los que entran en contacto las relaciones entre oralidad y escritura, como también las figuras del autor, el intérprete, el copista y el colector, entre otras posibles representaciones.
\end{abstract}

KeYwORDS: Colección de Folklore 1921, popular PALABRAS-CLAVE: colección de Folklore 1921, lyric, autor, singer, collector lírica popular, autor, cantor, colector

La aproximación a las manifestaciones populares en el discurso poético iberoamericano requiere una precisión del alcance de «lo popular». Con ese propósito, defino como populares a los poemas (de carácter lírico y narrativo) que son portadores de un componente oral de sustancial importancia ya sea en su génesis, en su recepción o en su transmisión, en ámbitos rurales de cultura tradicional oral o en ámbitos urbanos a través de la comercialización de impresos de muy bajo coste. Estos poemas se transmiten al margen de los circuitos letrados, su autor es anónimo o conocido pero ajeno a los cenáculos literarios. Esta definición relativiza la operatividad de la distinción popular tradicional que había realizado Ramón Menéndez Pidal (1953) en sus estudios sobre 
romancero y se conecta en cambio con las indagaciones teóricas desarrolladas a lo largo del siglo XX que ponen en diálogo (y en tensión) la literatura oral producida y reproducida en sociedades rurales con las prácticas populares surgidas de los ámbitos urbanos y la cultura de masas. En este sentido, no solo deben ser consideradas como populares las manifestaciones de la literatura tradicional asociadas con la transmisión oral, la ausencia de autor, la reelaboración comunitaria y las formas de vida rurales, sino también que debe ser atendido el concepto de literatura popular impresa que en su misma formulación complejiza la distinción entre lo «popular» y lo «culto» al incorporar un nuevo factor al proceso de creación y difusión de los productos: la imprenta ${ }^{1}$. En todos los casos, para efectuar el estudio de estos textos se debe indagar en las relaciones entre oralidad, escritura manuscrita e imprenta, operadas en el circuito de producción textual y sus conexiones con los ámbitos letrados y populares.

En esta ocasión propongo abordar el problema de la autoría en textos poéticos procedentes de la Colección de Folklore argentino (1921) producto de una encuesta realizada a los maestros de escuelas rurales de todo el territorio nacional con el propósito de documentar la literatura y cultura de raigambre hispánica en un momento en que la llegada de inmigrantes europeos, portadores de diferentes lenguas y tradiciones, hacía peligrar la impronta lingüística y cultural del joven país independiente.

La sociedad argentina de ese período puede ser caracterizada como «nueva», resultado de proyectos poblacionales y migraciones internas y externas. Esta condición determinó que la cultura popular, y la poesía en particular, se manifestaran en distintas tradiciones superpuestas. Una tradición hispánica procedente del período colonial se asentó en el noroeste del país, área de población más antigua en la que fueron documentados romances y coplas tradicionales. Paralelamente, una tradición criolla heredera de la hispánica tuvo expresiones autóctonas en relación con los movimientos

\footnotetext{
${ }^{1} \mathrm{Si}$ bien la impronta pidaliana fue clave para el estudio de la poesía oral hispánica y para sistematizar el abordaje de su género más representativo, el romancero, en la segunda mitad del siglo XX se tornó necesario incorporar nuevas búsquedas teóricas sobre la definición de lo popular y la pretensión de hallar su autenticidad. En la actualidad, estos interrogantes continúan ofreciendo miradas en tensión desde disciplinas y posturas ideológicas disímiles entre las que cabe destacar los recorridos de historiadores como Peter Burke (1991), Carlo Ginzburg (1989) y Roger Chartier (1994), que retrotraen la interrogación sobre lo popular a la génesis de la Europa moderna, en conexión con el concepto de clase social, la masificación de la lectura y los mecanismos de apropiación. Asimismo, han sido significativos los postulados de la filosofía política, desde Antonio Gramsci (1967) quien plantea la reflexión sobre lo popular en términos de dominación, rescribiendo la dicotomía entre alta y baja cultura con las categorías de clase dominante y clases subalternas, hasta los trazos de la polémica entre los representantes de la Escuela de Frankfurt, especialmente la visión condenatoria de Theodor Adorno (1984) a la masificación de la cultura y la compleja simpatía con que Walter Benjamin (1989) analiza las modificaciones que se operan en el arte a partir del desarrollo de nuevas tecnologías. Finalmente, en una lista que no pretende ser exhaustiva, se añaden los análisis de antropólogos como Clifford Geertz (1991), su definición de cultura desde una postura integradora dentro de la cual pueden describirse los fenómenos que la constituyen, Néstor García Canclini (1982 y 1990), a partir de su análisis detenido del proceso de encuentro de los estados con las masas promovido por las tecnologías comunicacionales y la dimensión teatral que está implicada en el proceso; semiólogos como Umberto Eco (1968), en su caracterización de apocalípticos e integrados en cuanto a las posibilidades de recepción de la cultura de masas, o la visión de la cultura popular conectada con la parodia y el carnaval que propone Mijail Bajtín (1987). Cada una de estas perspectivas intenta responder las preguntas básicas referidas a dónde está el pueblo o cuál es el límite entre cultura letrada y cultura popular en una contienda que continúa en nuestros días y que persigue, al decir de Fredric Jameson (1990), el difícil objetivo de definir los productos culturales que hacen felices a las masas. De acuerdo con lo planteado en la mayoría de estos textos, nos enfrentamos a la necesidad de una aproximación dialógica en el sentido de no dogmática, no academicista, en interacción permanente con el objeto, con las diversas disciplinas y con el contexto.
} 
independentistas (romancero criollo, pero también décimas y coplas). Por último, una tradición europea se incorporó entre fines del siglo XIX y principios del XX con el denominado aluvión inmigratorio. Esta última corriente impregnó todo lo anterior con nuevos temas procedentes especialmente de España, pero en contacto con diversas formas populares de otros países como Italia, Francia y Portugal ${ }^{2}$.

La denominada Colección de Folklore o Encuesta del Magisterio, reunida en Argentina en 1921, fue el resultado de un proyecto institucional interesado en conservar las tradiciones vernáculas en un momento en que el flujo de inmigrantes, procedentes de distintos países europeos, estaba cambiando la cultura popular de la sociedad postcolonial. El paso siguiente constituyó en utilizar este acervo como un instrumento didáctico para formar las nuevas generaciones de argentinos de múltiple procedencia. Las así llamadas «tradiciones nacionales» designaban el acervo folklórico de origen hispánico y los elementos procedentes de las culturas originarias (muy exiguos en el caso de Argentina), destinado a operar como un escudo protector de la «argentinidad».

En este proyecto tiene primacía absoluta el componente cultural hispánico. Si bien las primeras reflexiones sobre la lengua y la cultura españolas que tienen lugar en Argentina, inmediatamente después de la Independencia, exigen la emancipación lingüística y se encuentran signadas por una valoración negativa que aspira a una diferenciación tajante con la metrópolis, pasados unos pocos años se produce un movimiento que podemos denominar como un «retorno» a España ${ }^{3}$. Alfredo Rubione $(2006,19)$ señala que:

es difícil saber con precisión cuándo la elite argentina retornó a España, pero es indudable que hacia fines del siglo XIX un sector protagónico de la clase gobernante, de modo coincidente con el proceso de organización y consolidación del estado nacional, comenzó a valorar aspectos de la cultura española e intentó situarla como referente, norma y fundamento del discurso institucional de la cultura oficial argentina. Los cimientos del edificio nacional, estaban profundamente arraigados en un espacio y una cultura a la que percibieron como Madre Patria.

En torno a 1910, España ofreció a muchos pensadores argentinos un modelo para la construcción de una identidad que, en pleno proceso inmigratorio ultramarino, operaría como autoconciencia de una clase dirigente interesada en homogeneizar la diversidad y en afincar su proyecto en una tradición sólida que no pudiera ser subsumida fácilmente por otras tradiciones, por ejemplo la italiana o el american way of life norteamericano que se impondría rápidamente en el período de entreguerras.

Todos los aparatos del estado se encargarían de reforzar la pertenencia al orbe hispánico y las instituciones educativas se ocuparían de instruir a maestros y profesores para que borraran las divergencias entre la modalidad dialectal rioplatense y la madrileña. Al mismo tiempo se reforzaba el valor simbólico de la lengua como expresión privilegiada de la nacionalidad, entendida en un sentido de unidad lingüística y racial con España. En esa operación se construyó un «nosotros» que fue piedra angular de la nacionalidad argentina sobre la base de una «comunidad natural preexistente» a la inmigración, la hispano-criolla, cuya auto-representación se reforzó para que lograra ser impuesta a los recién llegados mediante el sistema educativo, conjuntamente con la proliferación de símbolos, íconos, valores y prácticas.

\footnotetext{
${ }^{2}$ Puede verse un panorama de la superposición de estos distintos estratos culturales en Chicote (2012).

${ }^{3}$ Los párrafos siguientes reproducen lo publicado en Chicote (2013).
} 
En 1921 el Ministerio de Educación de la Nación, por iniciativa de Ricardo Rojas, encargó a los maestros de las escuelas nacionales de todo el país la recolección de los elementos folklóricos que encontraran en su jurisdicción. Junto con las indicaciones para la realización de la encuesta se envió un modelo de clasificación de los materiales recolectados que constaba de cuatro ítems: 1. Creencias y costumbres, 2. Narraciones y refranes, 3. Arte, y 4. Ciencia popular. La sección Arte incluía todo lo referente a poesía, entre lo que se especificaban los siguientes géneros: 3.A. Poesías y canciones; 3.A.a. Romances, poesías de los aborígenes, poesías populares de género militar o épico que canten escenas, episodios, luchas, costumbres, etc., de las invasiones inglesas, guerra de la independencia y guerras civiles posteriores; 3.A.b. canciones populares; 3.A.c. canciones infantiles; 3.B. Danzas populares con o sin acompañamiento de canto. La tarea se realizó con pleno éxito, y sus pliegos, que actualmente se conservan en 4000 legajos (más de 88.000 folios) en el Instituto Nacional de Antropología, constituyen un valiosísimo testimonio, rescatado de la memoria popular pocos años antes de que el «progreso», traducido en comunicación vial y tecnologías mediáticas, comenzara a violar el aislamiento de distintas poblaciones y a modificar sus tradiciones. Si bien la documentación adolece de errores debidos a la inexperiencia de los improvisados encuestadores, o a la falta de especificación en las instrucciones, ya que a veces se tornaba difícil encasillar el material en uno de los cuatro ítems, estos documentos conforman uno de los archivos folklóricos más ricos del continente. Años después, nuevamente por iniciativa de Ricardo Rojas, se efectuó la catalogación de la encuesta en el Instituto de Literatura Argentina de la Facultad de Filosofía y Letras de Universidad de Buenos Aires ${ }^{4}$. Posteriormente, el Ministerio de Educación utilizó algunos textos para publicar antologías folklóricas argentinas, destinadas a la difusión de poesía folklórica en los niveles primario y secundario de enseñanza ${ }^{5}$.

Para indagar diferentes aspectos relacionados con la autoría de los textos reunidos se podrían formular los siguientes interrogantes: ¿Puede el análisis de este corpus agregar algo a las discusiones sobre el concepto de autor de larga data en los estudios de literatura popular? ¿Cómo se inserta el concepto de autor en el corpus que acabo de caracterizar? ¿Cómo se construye en los textos populares la cadena de mediaciones entre emisor, mensaje y receptor? ¿Actúan estas categorías como los modos de posibles de integración que una sociedad nueva podía tener en el concierto de la cultura universal con mayores o menores marcas de eurocentrismo? ¿Qué perfiles específicos adquieren las distintas denominaciones del autor, el intérprete, el colector y el editor, entre otras posibles representaciones?

En primer lugar, podemos diferenciar figuras específicas, si nos referimos a un circuito de transmisión puramente oral o a un circuito mixto de transmisión escrita-oral. Con respecto al autor del poema popular resulta muy difícil establecer la adscripción de quién creó el texto, ya que esta varía de acuerdo con la antigüedad del mismo. En el caso de los romances de origen medieval que se transmitieron oralmente en la Península Ibérica desde los siglos XIV y XV, se fijaron por escrito en los cancioneros y pasaron a América tanto en los libros y las voces de los conquistadores, como en las distintas olas

\footnotetext{
${ }^{4}$ El ordenamiento se realizó por provincia y por maestro, y recibe el título de Catálogo de la Colección de Folklore, Buenos Aires, Universidad de Buenos Aires, 1925-38. Como ejemplo de antología didáctica puede citarse la Antología Folklórica Argentina (para escuelas de adultos), Buenos Aires, Consejo de Educación, 1940.

${ }^{5}$ Me ocupé de estas antologías en el artículo citado (Chicote, 2013).
} 
migratorias hasta principios del siglo XX, el autor es anónimo y colectivo, ya que el poema es producto de sucesivas reelaboraciones. Las variantes con que se documentan los mismos temas son el reflejo de las modificaciones que se operan en los contenidos de los textos, en relación con su adaptación a los distintos contextos históricos.

Podemos tomar como ejemplo el romance de «Las señas del Esposo» o «La Catalinita», que es el tema más difundido en la tradición argentina. Mercedes Díaz Roig $(1990,227)$ nos da cuenta del origen tardío de este romance compuesto a partir de un motivo muy caro a la literatura universal desde La Odisea: el marido que regresa de la guerra y somete a su esposa a pruebas de fidelidad antes de hacerse conocer. Ampliamente documentado en todo el país, circula con variantes de intriga, a pesar de que en todas las versiones se mantiene el motivo central del poema: el reencuentro de los esposos separados por la guerra, las pruebas de fidelidad y el reconocimiento final. En las referencias a la localización de la acción, ya sea el lugar donde se produce el encuentro entre Catalina y el soldado, la partida del marido o las circunstancias de su muerte, observamos un lento proceso de tradicionalización hasta que en una de las versiones recolectadas en la Colección de Folklore, la esposa se encuentra con el soldado, «En una noche de luna estando en el Paraguay» (Moya, I, 481). Se mencionan además distintas guerras y distintos protagonistas: Francia, España, el rey, los moros, los turcos, pero también Brasil, Paraguay, las guerras de la Independencia americana, se alternan en los versos del romance, todas marcas espacio-temporales que permiten apreciar las variantes que contribuyen a determinar una realización histórico-geográfica en su fluir de tradicionalidad. En una versión de San Juan documentada en la Colección de Folklore (Moya, I, 496), aparece intercalada, después del pedido de recado del soldado, una estrofa lírica que no se relaciona con el desarrollo de la intriga, posiblemente contaminación con una canción de moda:

Rema, rema marinero, que me gusta tu remar, hay muchachas como flores, ¿dónde vamos a parar?

Tal como se puede apreciar, no hay indicios en los textos de un autor primigenio sino una cadena de modificaciones producidas a lo largo de los siglos.

Un movimiento análogo se puede evidenciar en las coplas que proceden de la tradición hispánica, pero tienen una vida independiente en América en la que se manifiestan transformaciones producto del contexto cultural y social. Sirvan de ejemplo estas coplas documentadas en la escuela N1 105, Pcia. de Buenos Aires, en las que conviven la temática amorosa con los cambios tecnológicos:

Poco se me da

De dormir en la vereda

Que venga el ferrocarril

Y me lleve con sus ruedas

Un arbolito sin hojas

¿qué sombra me puede hacer?

$\mathrm{Y}$ un mocito forastero

¿qué cariño me puede tener?

Señora, yo soy un pobre

Oficial de carpintero 
Que no tengo más que darle

Que viruta para el fuego.

Con respecto a las décimas, entre las recordadas por los cantores y recitadores también aparecen las de tono romántico con algunas de creación local más reciente.

Hoy mi triste corazón

De pesares sin cadenas

Y cruelmente se enajena

De mi gloria una pasión

Que tristes recuerdos son

Los que me hacen suspirar

Obligándome a llorar

Sin ser, sin vida y sin alma,

Hoy me voy a separar.

(Escuela N. ${ }^{\circ}$ 92, Dolores, Pcia. de Buenos Aires, recitado por Loreta Baigorria, 100 años)

Es muy lindo divisar

El sol en el horizonte

Y escuchar allá en el monte

Los pajaritos cantar

Ver un paisano ensillar

A su brioso redomón

Y oír cantar una canción

Y contemplar a una china

Que se encuentra en la cocina

Preparando un cimarrón.

(Escuela n. 7 Bahía Blanca, recitada por Manuel Suárez Gordillo, 65 años)

Se puede observar la preponderancia de la primera persona en los poemas citados. Esto se debe a las posibilidades que ofrece el yo lírico de borrar los límites autorales y entrelazar las voces de autor y emisor, ya sea recitador o cantor. Por otra parte, no debemos olvidar el componente musical y la presencia del cantor encargado de transmitir estos poemas, tal como se tematiza en esta octava:

Ya que encerré la tropilla

Y que recogí el ganado

Voy a templar la guitarra

Para exponer mi deseo

Cielito, cielito que sí

Mi asunto es un poco largo

Para algunos será alegre

Y para otros amargo.

El cantor, generalmente acompañado por un instrumento musical (guitarra, bombo o caja), selecciona sus canciones a partir de sus gustos, su pericia estética, su conocimiento del repertorio en su conjunto y de la dinámica particular de cada género para intervenir en los poemas-canciones y dejar también su impronta de autoría. En las canciones populares el cantor se siente con pleno derecho a modificar textos y melodías. También debemos recordar que en el caso de los poemas populares, los receptores, que aparecen con el rol de informantes en las encuestas, tienen un sentido de pertenencia que 
determina la introducción de modificaciones contribuyendo, ellos mismos, a distintos procesos de selección mnemotécnica que van modelando el discurso poético y dan lugar a las diferentes versiones de un mismo tema poético. Lamentablemente, no contamos con registros de este tipo de intervenciones.

Si abandonamos las observaciones sobre el circuito de transmisión oral y pasamos a considerar el registro y la fijación escrita de los poemas populares, debemos pensar en nuevas mediaciones. En este punto es clave la figura del colector, la maestra o el maestro en este caso, que realiza los registros de acuerdo con una concepción teórica y metodológica determinada sobre la fijación de los textos y los contextos de producción en cuyo marco opera. A continuación copio el encabezamiento más frecuente que acompaña las documentaciones:

\author{
Narraciones y refranes \\ Localidad: Estancia Janzón, 9 de Julio. Pcia. de Buenos Aires \\ Nombre del director que lo remite: Josefa Jeinses \\ Nombre de la persona que lo narró: Rosa de Gómez \\ Edad de la persona: 33 años \\ Si el maestro sabe que lo conocen otras personas: lo conocen los habitantes de esta región
}

Las primeras documentaciones folklóricas, realizadas en el siglo XIX y a principios del siglo $\mathrm{XX}$, consignaban pocos o nulos datos de la circunstancia en que fueron efectuadas las recopilaciones. Asimismo, los textos resultantes sufrieron muchas intervenciones por parte de los colectores que trataron de «mejorarlos» desde una perspectiva filológica que intentaba conectarlos con las tradiciones «cultas o letradas». Fueron regularizadas la medida de los versos y las rimas, y cambiados vocablos que consideraban inapropiados por proceder de usos vulgares o no responder a las normas fijadas por las academias. A esto debe agregarse también que los colectores no contaban con los instrumentos adecuados para realizar documentaciones exhaustivas que incluyeran variantes textuales, música y circunstancias de actualización. Algunos científicos señalaron cómo copiaban al dictado lo recitado por los comarcanos, y puntualizaron la necesidad de que musicólogos especializados los acompañaran en los trabajos de campo para documentar las melodías. No sabemos hasta qué punto los textos registrados son fidedignos representantes de la tradición o si fueron en algunos casos recreaciones «cultas», ya que carecemos por lo general de noticias relativas a la emisión de las versiones. Pero, a pesar de la ausencia de registros sistemáticos, la interacción oral de la que partieron esos textos, el contexto que determinó no solo su existencia sino también su vigencia funcional se filtra en las descripciones y en las explicaciones de los folkloristas. En muchos casos es posible vislumbrar en un segundo plano, detrás de los datos, el ámbito popular del que provienen los poemas, como telón de fondo.

A medida que avanza el siglo XX se perfeccionan las técnicas de registro que incluyen grabaciones ${ }^{6}$ y las consecuentes desgrabaciones que marcan la incidencia de la cultura letrada de una nueva figura, el investigador quien escucha los documentos influenciado por su conocimiento previo de la canción. En este punto comienzan a tener una presencia fundamental en la propagación de los poemas populares las transmisiones radiofónicas y discográficas que se van a desarrollar a lo largo del siglo XX y van a dar lugar a la cultura de masas. Volviendo a la Colección de Folklore, sus registros permiten

\footnotetext{
${ }^{6}$ En Argentina podemos señalar la fecha temprana de 1905 para los primeros documentos sonoros de canciones populares realizadas por el antropólogo Robert Lehmann-Nitsche en la ciudad de La Plata (Chicote-García, 2008).
} 
constatar que, a pesar de que en 1921 no existía la radio y los millones de argentinos que vivían dispersos en distintas comunas rurales habían tenido pocas oportunidades de escuchar la voz de Carlos Gardel, si no fuera en un disco de vinilo, en un pueblo de los valles calchaquíes fueron recogidas dos milongas cuyos autores el maestro reconoció como Carlos Gardel y José Razzano (Chamosa, 58). La fuente en este caso es de suma utilidad para mostrar una temprana red de comunicaciones culturales, producto de migraciones internas en las distintas regiones del país que se efectuaron en muchos casos en el marco de los trabajos temporarios del ámbito agropecuario o del tendido de vías de comunicación que necesitaban constantes traslados de trabajadores.

Entre las diferentes representaciones autorales que constituyen la cadena, no debemos olvidar la que surge del proceso de clasificación y visibilización del archivo. En este punto entran en juego otras mediaciones: el investigador se constituye en editor que es el encargado de ordenar y mostrar los textos, nunca de forma ingenua sino intencionada desde una perspectiva teórica y con una intencionalidad política. Los estudios más importantes efectuados a partir de esta documentación son los referidos a dos géneros populares paradigmáticos, el romancero y el refranero publicados por Ismael Moya (1941) y la recopilación de cantares históricos de Olga Fernández Latour (1960) que aporta datos de especial interés para la reconstrucción de la memoria de las distintas guerras del siglo XIX.

Por último, cabe señalar un movimiento más de los textos populares que es el retorno al acervo tradicional desde el libro o desde los soportes sonoros, para interactuar sobre ellos. En el caso del corpus estudiado, las Antologías publicadas por el Ministerio de Educación en la década de 1940 colaboraron con la perduración de los poemas de origen hispánico a través de la enseñanza escolarizada con la explícita función pedagógica de volver a enseñarlos a niños y adultos para fortalecer los rasgos de la «argentinidad criolla» en peligro por la influencia de lenguas y culturas extranjeras.

Para concluir quiero tomar la cita de un trabajo reciente de Fabio Espósito y Ely di Croce (2018) para realizar una última reflexión sobre el concepto de autoría en la poesía popular:

La transformación del conjunto de manifestaciones orales de la cultura popular en una fuente documental escrita no se debe al simple acto de recolección y transcripción de un informante letrado, sino que supone una compleja red de mediaciones tanto políticas como culturales.

Quienes nos dedicamos al estudio de la poesía popular no podemos ignorar la red de mediaciones a través de la que nos acercamos a sus manifestaciones. Esta red está constituida por distintas fases tales como selecciones linguiísticas, selecciones genéricas, posicionamientos teóricos y metodológicos tanto de recolección como de fijación textual, diferentes etapas de catalogación y visibilización, y la intervención institucional, ya sea con fines formativos e investigativos, a la que pertenecemos. El circuito autoral descripto hasta aquí no puede ser escindido de las fases mencionadas ya que se encuentra en la raíz misma de la secuencia de mediaciones, y sus diferentes configuraciones solo pueden ser entendidas en el interior de este proceso. 


\section{BIBLIOGRAFÍA}

AdORno, Theodor W., (1989): Teoría estética, Buenos Aires, Hyspámerica.

ANTOLOGÍA FOLKLÓRICA ARGENTINA (para escuelas primarias) (1940): Buenos Aires, Guilllermo Kraft Ltda.

ANTOLOGÍA FolKLóRICA ARGENTINA (para escuelas de adultos) (1940): Buenos Aires, Guilllermo Kraft Ltda.

BAJTIN, Mijail (1987): La cultura popular en la Edad Media y en el Renacimiento, Madrid, Alianza.

Benjamin, Walter (1980): Iluminaciones II. Poesía y capitalismo, Madrid, Taurus.

BURKE, Peter (1991): La cultura popular en la Europa moderna, Madrid, Alianza.

CATÁLOGO DE LA COLECCIÓN DE FOLKLORE (1925-38), Buenos Aires, Universidad de Buenos Aires.

Chamosa, Oscar (2012): Breve historia del folklore argentino (1920-1970), Buenos Aires, Edhasa.

CHARTIER, Roger (1994): Libros, lecturas y lectores en la Edad Moderna, Barcelona, Alianza.

Chicote, Gloria (2012): «La lírica popular-tradicional argentina: límites difusos», Olivar, n. ${ }^{\circ} 18$, pp. 255-275.

CHicote, Gloria (2013): «El camino del sur: temas y géneros seculares en el cancionero popular infantil de la Argentina», Presencia del cancionero infantil en la lírica hispánica, Pedro Cerrillo y César Sánchez Ortiz (coords.), Cuenca, Universidad de Castilla-la Mancha, pp. 249-264.

Chicote, Gloria y GarcíA, Miguel Ángel (2008): Voces de tinta. Estudio preliminar y antología comentada de Folklore Argentino (1905) de Robert Lehmann-Nitsche, Berlín-La Plata, Ibero-Amerikanisches Institut- Edulp.

Eco, Umberto (1990): Apocalípticos e integrados, Barcelona, Lumen.

EsPósITO, Fabio y Di CROCE, Ely (2018): «La lírica en el Catálogo de la Colección de Folklore», en «Lyra minima» de la voz al papel, Gloria Chicote, Mariana Masera, Verónica Stedile Luna (coords.), México, Universidad Nacional Autónoma de México.

FERNÁNDEZ LATOUR, Olga (1960): Cantares históricos de la tradición argentina, Buenos Aires, Instituto Nacional de Investigaciones Folklóricas.

GARCía CANCLINI, Néstor (1990): Culturas híbridas, México, Grijalbo.

GEERTZ, Clifford (1991): La interpretación de las culturas, Buenos Aires, Gedisa.

GINZBURG, Carlo (2016): El queso y los gusanos, Madrid, Ariel.

GRAMSCI, Antonio (1974): Literatura y cultura popular, Buenos Aires, Cuadernos de Cultura Revolucionaria.

JAMERSON, Fredric (1990): Late Marxism, New York, Verso.

MENÉNDEZ PIDAL, Ramón (1953): Romancero hispánico (Hispano, portugués, americano y sefardí). Teoría e historia, 2 vols., Madrid, Espasa-Calpe.

MoYA, Ismael (1941): Romancero, Buenos Aires, Universidad de Buenos Aires.

MoYA, Ismael (1944): Refranero, Buenos Aires, Universidad de Buenos Aires. 
Rubione, Alfredo (2006): «Retorno a España», en La crisis de las formas, V, Noe Jitrik (dir.), Buenos Aires, Emece, pp. 19-42.

Fecha de recepción: 24 de abril de 2019

Fecha de aceptación: 28 de agosto de 2019

$$
9
$$

